\title{
Gas-non-Newtonian Liquid Flow Through Horizontal Pipe - Gas Holdup and Pressure Drop Prediction using Multilayer Perceptron
}

\author{
Nirjhar Bar, Sudip Kumar Das* \\ Department of Chemical Engineering, University of Calcutta, Kolkata, 700009, India
}

\begin{abstract}
Prediction of the gas holdup and pressure drop in a horizontal pipe for gas-non-Newtonian liquid flow using Artificial Neural Networks (ANN) methodology have been reported in this paper from the data acquired from our earlier experiment. The ANN prediction is done using Multilayer Perceptrons (MLP) trained with three different algorithms, namely: Backpropagation (BP), Scaled Conjugate gradient (SCG) and Levenberg-Marquardt (LM). Four different transfer functions were used in a single hidden layer for all algorithms. The Chi-square test confirms that the best network for prediction of gas holdup is when it is trained with Levenberg-Marquardt (LM) algorithm in the hidden and output layer with the transfer function 1 in hidden layer having 5 processing elements. The Chi-square test also confirms that the best network for prediction of pressure drop is when it is trained with Backpropagation (BP) algorithm in the hidden and output layer with the transfer function 4 in hidden layer having 15 processing elements.
\end{abstract}

Keywords Gas Holdup, Pressure Drop, Gas-Non-Newtonian Liquid Flow, Backpropagation, Scaled Conjugate Gradient, Levenberg-marquardt

\section{Introduction}

The co-current gas-liquid flow through pipeline has many different industrial applications, like chemical, petrochemicals and nuclear plants, crude oil pipelines etc. The gas-liquid flow become very complex in nature and the three important hydrodynamic parameters are the void fraction, pressure drop and flow regime. These parameters have been studied extensively by experimentally and theoretically. In order to accurately estimate the pressure drop and void fraction, it is necessary to know the flow pattern accurately[1]. Enormous literatures available in this field have been summarized in several books[2-5]. Most of these studies are with gas-Newtonian two-phase flow. However, very little information is available when the liquid is non-Newtonian in nature. The experimental studies on the hydrodynamic parameters estimation for gas-non-Newtonian liquid flow though horizontal pipeline are reported by only few researchers[6-33]. All these studies show that the gas-non-Newtonian liquid two-phase flow hydrodynamics in pipes behave differently from the hydrodynamics of a gas-Newtonian liquid flow. Ward and Dallavalle[6] observed drag reduction by injecting air into clay suspensions

* Corresponding author:

drskdaspapers@hotmail.com (Sudip Kumar Das)

Published online at http://journal.sapub.org/ajfd

Copyright (C) 2012 Scientific \& Academic Publishing. All Rights Reserved flowing in laminar regime. Oliver and Young Hoon[7] reported the several differences between the flow patterns that occur in gas-Newtonian and gas-non-Newtonian liquid flow. According to their experimental findings Newtonian liquids tend to produce circulating patterns whereas the non-Newtonian liquids produce stream line deflections around the gas slug. They tried to correlate their experimental data by Lockhard-Martinelli correlation[8]. Rosehart et al.[9] also observed similar deviation. Mahalingam and Valle[10] reported that the flow patterns for-gas-Newtonian liquid flow were similar to that of gas-Newtonian liquid system. They observed that the two-phase pressure drop were greater than those of the gas-Newtonian liquid flow. They also observed a sharp increase in pressure drop in the bubble flow region but as the flow pattern changed to slug and wavy flow region, increase in air velocity resulted in sharp decrease in pressure drop, the gas holdup increased with increasing gas flow rate and decreasing pseudo plasticity. Rosehart et al.[11] studied two-phase gas -non- Newtonian liquid slug flow using drag reducing polymer solution, i.e., liquid phase containing small amount of polyacetamide, a long chain polymer. They reported that the drag reduction in two-phase flow greater than in single phase flow and also showed the importance of the acceleration term in the axial pressure gradient.

Srivastava and Narsimhamurthy[12,13] reported their experimental studies on the two-phase gas-non-Newtonian liquids in horizontal pipes with turbulence promoters and 
analysed their pressure drop and holdup data using modified Lockhart-Martinelli[8] correlation. Tyagi and Srivastava[14] analyzed the pressure drop data for annular flow of gas-non-Newtonian liquid and proposed an analytical model relating the film thickness with flow rates, physical properties of the fluids and the energy losses. Otten and Fayed $[15,16]$ reported studies on both the pressure drop and drag reduction and later on the slug velocity and frequency in concurrent flow of air-carbopol 941 solution. Heywood and Richardson[17] studied the flow of air-kaoline solutions and observed a large reduction in pressure drop by injecting the air into the slurry. Similar drag reduction was observed by Farooqi et al.[18] for air-anthracite slurry flow. Eisenberg and Weinberger[19] developed an expression for the prediction of pressure drop and holdup for annular two-phase flow of gas-non-Newtonian liquid. They modified the Lockhart-Martinelli correlation to take into account the shear rate dependence on the apparent viscosity of the liquid phase. Heywood and Charles[20] published a gas-non-Newtonian liquid stratified flow model to predict the liquid holdup and pressure drop. Farooqi and Richardson[21,22] reported their experimental studies on gas-Newtonian and gasnon-Newtonian liquid flow and analysed their data by modifying the Lockhart-Martinelli correlation. Chhabra et al.[23] studied the co-current flow of air and shear thinning china clay suspensions in water in a large diameter horizontal pipe. They observed that the Faaooqi and Richardson[22] correlation agrees well with the experimental two-phase data. Chhabra et al.[24] studied the pressure drop and hold up in isothermal two-phase flow of air and aqueous polymer solution in horizontal pipe. Their experimental results agreed well the equations suggested by Farooqi and Richardson[22]. Das et al.[25,26] studied gas-non-Newtonian liquid flow through horizontal tube and developed empirical correlation for the prediction of two-phase pressure drop and holdup. Dziubinski[27] studied experimentally and presented an expression of drag ratio for two-phase pressure drop of intermittent gas-non-Newtonian liquid flow based on the loss coefficient concept. Jinming and Jingxuan[28] experimentally studied the two-phase gas-non-Newtonian liquid such as sewage sludge and black water in sewers in pipes and modified the Lockhart-Martinelli parameter for the prediction of two-phase pressure drop. Ruiz-Viera et al.[29] studied lubricating grease-air flow through different geometries of smooth and rough surfaces and observed drag reduction. Xu et al.[30] studied gas-non-Newtonian liquid flow through horizontal tube of $50 \mathrm{~mm}$ diameter. $\mathrm{Xu}$ et al.[31] studied co-current air-non-Newtonian liquid flow in inclined tubes of different diameters. $\mathrm{Xu}$ et al.[32] observed the drag reduction by gas injection to non-Newtonian liquid in stratified and slug flow regimes. They also proposed models for each flow regimes to predict the two-phase pressure drop and drag reduction. Jia et al.[33] reported the three dimensional computational multiphase fluid dynamics CMFD simulations to estimate the two-phase pressure drop in slug gas-non-Newtonian liquid flow system. ANN models have been extensively studied in different fields of engineering, finance etc. in last two decades with an objective of achieving human like performance. ANNs are derived from the biological counterparts, and based on the concept that a highly interconnected system of simple processing elements, known as nodes or neurons, which are able to learn highly complex nonlinear interrelationships existing between input and output variables of the data set[34].

Cai et al.[35] used neural network to identify flow regimes in air-water flow. Leib et al.[36] used ANN model along with the mixed-cell model to predict the slurry bubble column performance for Fischer-Tropsch synthesis. Various ANN modelling were used to predict various hydrodynamic parameters in packed bed and fluidized bed reactors[37-40]. Shippen and Scott[41] used ANN as predictive tool to predict liquid holdup in two-phase flow. Osman and Aggour[42] developed ANN model to predict the pressure drop for gas-liquid flow through horizontal and near horizontal pipes from a data bank consisting of 450 sets of oil field data. They observed that the ANN model predict the pressure drop very accurately than the existing available correlations and mechanistic models. Malayeri et al.[43] used radial basis function neural network to predict the cross-sectional and time-averaged void fraction at different temperature in air-water two-phase flow. Alizadehdakhel et al.[44] studied gas-liquid flow through $2 \mathrm{~cm}$ diameter tube and they modelled using CFD and ANN techniques. They concluded that the prediction of two-phase pressure drop using CFD is more accurate than the ANN prediction and moreover it gives the insight of two-phase flow. Shaikh and Al-Dahhan[45] observed that the ANN prediction of the gas holdup in bubble column reactors give better predictability than the correlations available in the literature. Nasseh et al.[46] used neural network optimized by genetic algorithm to predict the pressure drop in venturi scrubbers.

The pressure drop for non-Newtonian liquid and gas-liquid flow through different piping components like elbow, orifice, gate valve and globe valve was successfully predicted by Bar et al.[47,48] using the same Multilayer Perceptron. The neural network used by them had four different transfer functions in a single hidden layer. Only backpropagation algorithm was used for training. Bar et al.[49] also used the same method algorithm to predict the frictional pressure drop for non-Newtonian gas-liquid flow through $45^{\circ}$ bend in the horizontal plane.

ANN models can able to learn from examples, incorporate large number of variables, and provide an adequate and quick response to the new information. The advantages of neural networks are (1) the ability to represent both linear and nonlinear relationships, (2) the ability to learn these relationships directly from the data used, (3) the MLP network can be used to create a model that correctly maps the input to the output using historical data so that the model can predict the unknown output, (4) The prediction by the trained network are alternative to experimentation and save a lot of time that may have been consumed[48]. Various algorithms are available for training of the MLP neural networks and 
this algorithm is especially capable of solving predictive problems[49, 50]. Recently five different algorithms were used to predict the frictional pressure drop for gas-non-Newtonian liquid flow through $180^{\circ}$ bend in the horizontal plane[51].

From the literature review it was clear that only very few prediction of the hydrodynamic parameter on gas-liquid flow based on ANN were reported. This paper deals with applicability of ANN to predict the two-phase gas holdup and pressure drop of gas-non-Newtonian liquid flow through horizontal pipeline.

\section{Experimental 7}

Detail experimental setup has been reported in our earlier work[25,26,52]. The setup consists of a liquid storage tank $\left(0.45 \mathrm{~m}^{3}\right.$ capacity) fitted with a propeller type stirrer. Air supply systems, test section, control, measuring system for flow rates, pressure and other accessories.

Table 1. Range of different data sets for all four different systems

\begin{tabular}{|c|c|}
\hline Measurement Type & Range \\
\hline Pipe diameter $\mathrm{D}_{\mathrm{t}}(\mathrm{m})$ & 0.01905 \\
\hline \multicolumn{2}{|c|}{ Physical properties of liquid } \\
\hline $\begin{array}{c}\text { Concentration of SCMC Solution } \\
\left(\mathrm{kg} / \mathrm{m}^{3}\right)\end{array}$ & 0.5 to 1.00 \\
\hline Flow behavior index & $0.6537 \leq \mathrm{n}^{\prime} \leq 0.8039$ \\
\hline Consistency index $\left(\mathrm{Ns}^{\mathrm{n}^{\prime}} / \mathrm{m}^{2}\right)$ & $0.108 \leq \mathrm{K}^{\prime} \leq 0.853$ \\
\hline Density $\left(\mathrm{kg} / \mathrm{m}^{3}\right)$ & $1004.97 \leq \rho \leq 1008.06$ \\
\hline Surface Tension $(\mathrm{kN} / \mathrm{m})$ & $106.98 \leq \sigma_{1} \leq 112.87$ \\
\hline \multicolumn{2}{|c|}{ Physical properties of air } \\
\hline Density $\left(\mathrm{kg} / \mathrm{m}^{3}\right)$ & 1.1611 \\
\hline Viscosity of Air $\left(\mathrm{Ns} / \mathrm{m}^{2}\right)$ & 0.0000186275 \\
\hline \multicolumn{2}{|c|}{ Flow Rate } \\
\hline Liquid Flow Rate $\mathrm{Q}_{1}\left(\mathrm{~m}^{3} / \mathrm{s}\right)$ & 0.00004 to 0.000284 \\
\hline Gas Flow Rate $\mathrm{Q}_{\mathrm{g}}\left(\mathrm{m}^{3} / \mathrm{s}\right)$ & 0.00001861 to 0.00043796 \\
\hline Two-phase gas holdup & $0.0657 \leq \alpha_{\mathrm{g}} \leq 0.4575$ \\
\hline $\begin{array}{c}\text { Two-phase pressure drop per unit } \\
\text { length }(\mathrm{kPa} / \mathrm{m})\end{array}$ & $1.68901 \leq \Delta \mathrm{P}_{\mathrm{tp}} / \mathrm{L} \leq 7.2965$ \\
\hline Total number of data points & 231 \\
\hline
\end{tabular}

The test section consists of a long horizontal straight Perspex tube of internal diameter $0.01905 \mathrm{~m}$ and $4.5 \mathrm{~m}$ long. The test liquids were prepared by dissolving the required amount of carboxy methyl cellulose (CMC) (high viscous grade - Loba Chemie Pvt. Ltd., Bombay, India) in tap water, stirring until a homogeneous solution was obtained and kept for more than $15 \mathrm{hrs}$ for aging. Biological degradation was prevented by adding trace amounts of formalin. Liquid temperature was controlled by cooling coil incorporated in the storage tank. The liquid pumped by a centrifugal pump to the test section and its flow rate was controlled by by-pass arrangement and measured by a set of rotameters connected parallel. Air was drawn from a compressor and its pressure was reduced to $103 \mathrm{kN} / \mathrm{m}^{2} \mathrm{~g}$ before injecting into the pipeline through $\mathrm{T}$ - entry. Flow rate was measured by a set of rotameters connected parallel. Static pressure at different points in the test section was measured by means of U-tube manometers containing Mercury beneath water. Arrangements for purging the air bubble and/or solutions in manometer line were also provided. Four aqueous solutions of CMC of approximate concentration of $0.5-0.1 \mathrm{~kg} / \mathrm{m}^{3}$ were used as the non-Newtonian liquid and atmospheric air was used as other fluids. Rheological properties, densities and surface tension of the liquid were measured using pipeline viscometer, specific gravity bottle and DuNouy's tensiometer respectively. The flow regimes predominantly in the plug and slug flow regime. Table 1 presents the range of variable investigated in experimental studies.

\section{ANN Structures and Its Optimization}

Figure 1 shows the schematic diagram of the ANN.

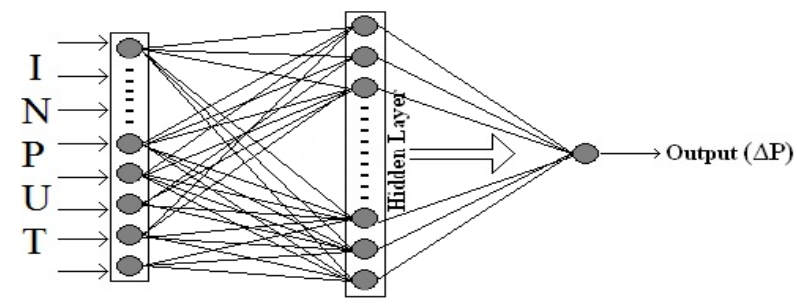

Figure 1. Schematic diagram of the ANN

The input parameters (from Table 1) are,

1) Liquid flow rate $-Q_{l}$

2). Gas flow rate $-Q_{g}$

3) Flow behaviour index $-n$

4) Consistency index- $K^{\prime}$

5) Liquid density $-\rho_{l}$

6) Surface tension of the liquid- $\sigma_{l}$

Air density $-\rho_{g}$ and air viscosity $-\mu_{g}$ and acceleration due to gravity $g$ are constant so it is ineffective as input parameter for ANN programming. Hence they did not take part in the analysis. The output parameter is either gas holdup, $\alpha_{\mathrm{g}}$ or two-phase frictional pressure drop, $\Delta \mathrm{P}_{\mathrm{tp}} / \mathrm{L}$.

Three different MLP algorithms were used for our analysis. These are known as Baclpropagation, Levenberg-Marquardt and Scaled Conjugate Gradient.

Backpropagation is discussed in detail in our earlier papers[47-49]. Generalized delta-rule algorithm[53] is used for the backpropagation. If $w_{i j}(t)$ is the value of connection weight in the hidden layer then the weights are updated using the following equation during the epoch number $(t+1)$,

$$
\Delta w_{i j}(t)=-\alpha \frac{\partial E}{\partial w_{i j}}(t)
$$

where $\mathrm{E}$ is the difference between the desired and the network output for any epoch. The above equation was modified by using a momentum term and is represented by

$$
\Delta w_{i j}(t)=-\alpha \frac{\partial E}{\partial w_{i j}}(t)+\mu \Delta w_{i j}(t-1)
$$

where $\Delta w_{i j}(t)$ represents the change of connection weights for the $j^{\text {th }}$ processing element in the hidden layer during epoch number $t$ with that of $i^{\text {th }}$ input. $\alpha$ is learning rate and 
$\mu$ is the momentum coefficient.

This is a second order learning algorithm that uses the method of optimization. If $N$ is the number of epochs and $n$ is the number of weights then the weight update equation is given as:

$$
\Delta w=\left(J^{T} J+\lambda I\right)^{-1} J^{T} e
$$

where $J$ is $(N \times 1) \times n$ Jacobian matrix and $e$ is $(N \times 1) \times 1$ error matrix, $I$ is the identity matrix and $\lambda$ is the combination coefficient. In this algorithm the only user dependent parameter is $\lambda$, which is set only in the beginning. It is not required for the user to modify the value of $\lambda$ during the training any more. When $\lambda$ is large the algorithm becomes steepest descent and when it is small the algorithm becomes Gauss-Newton. In this way the Levenberg-Marquardt algorithm combines the best features of these two algorithms but avoids most of their limitations.

This is a second order learning algorithm that uses the method of optimization. The SCG method is the advancement to that of the Conjugate Gradient (CG) method. In the Conjugate Gradient (CG) method the complexity of calculation for every epoch increases because of the line search to determine the correct step size, i.e., a line search requires several calculations of global error function or its derivative. In Scaled Conjugate Gradient (SCG) method there is no such line search required. It is fully automated and does not require the user to be involved during the training i.e., the user doesn't have to provide some of the values of the user dependent parameters (like $\alpha, \mu$ etc. as mentioned above). This reduces the complexity significantly. This method uses the model-trust region approach known from Levenberg-Marquardt algorithm to scale the step size.

\subsection{Performance of the ANN}

The performance of the network is checked using the following parameters:

Mean Squared Error (MSE),

$$
M S E=\frac{1}{N} \sum_{i=1}^{N}\left(x_{i}-y_{i}\right)^{2}
$$

Average Absolute Relative Error (AARE),

$$
\text { AARE }=\frac{1}{N} \sum_{i=1}^{N}\left|\frac{\left(y_{i}-x_{i}\right)}{x_{i}}\right|
$$

Standard Deviation $(\sigma)$,

$$
\sigma=\sqrt{\sum_{i=1}^{N} \frac{1}{N-1}\left[\left|\frac{\left(y_{i}-x_{i}\right.}{x_{i}}\right|-A A R E\right]^{2}}
$$

Cross-correlation coefficient $(R)$,

$$
R=\frac{\sum_{i=1}^{N}\left(x_{i}-\bar{x}\right)\left(y_{i}-\bar{y}\right)}{\sqrt{\sum_{i=1}^{N}\left(x_{i}-\bar{x}\right)^{2} \sum_{i=1}^{N}\left(y_{i}-\bar{y}\right)^{2}}}
$$

It has also been verified that the Cross-correlation coefficient between input and output is as close to unity as possible.

If the performance tested using the above statistical measures are very close to each then to find the optimum statistical performance Chi-square test $\left(\chi^{2}\right)$ will be conducted. It is represented as:

$$
\chi^{2}=\sum_{i=1}^{N} \frac{\left(x_{i}-y_{i}\right)^{2}}{y_{i}}
$$

The lowest value indicates the best model.

The MSE for each epoch for training and cross-validation in both cases are recorded for 5 different runs separately.

\subsection{Optimization of the ANN}

Hidden layer(s) in ANN have the ability to deal very complex and nonlinear problems. Single hidden layer ANNs creates a hyper plane. The greater numbers of hidden layers improve the closeness-of-fit while a smaller number of hidden layers improve the smoothness or extrapolation capability of the ANN[54]. White[55] indicated that a hidden layer with arbitrarily large quantity of neurons can perform accurately, whereas Walczak[56] observed that a network containing two hidden layers perfom better than the single hidden layer network for specific problems. Bansal et al.[57] and Tamura and Tateishi[58] observed that the single hidden layer can solve most of the problems for more input variables and outputs. In the present case single hidden layer is used. In the hidden layer the numbers of processing elements are optimized by varying the number 1 to 25 . Similar procedure was followed in our earlier studies by Bar et al.[47,48] and Bar and Das[51].The description of training procedure is elaborately described in our earlier paper[51]. Raw data are used as input variables without normalization. Initially the total data was randomized to prevent sampling error. Then $60 \%$ data points were used for training, $20 \%$ for cross-validation, $10 \%$ for testing and the rest used for prediction. Table 2 presents the four transfer functions used in the hidden layer. The output transfer function is given below,

$$
y=f(x)=x+b
$$

here $\mathrm{x}, \mathrm{y}$ and $\mathrm{b}$ are the input to the output layer, the final output and bias term respectively.

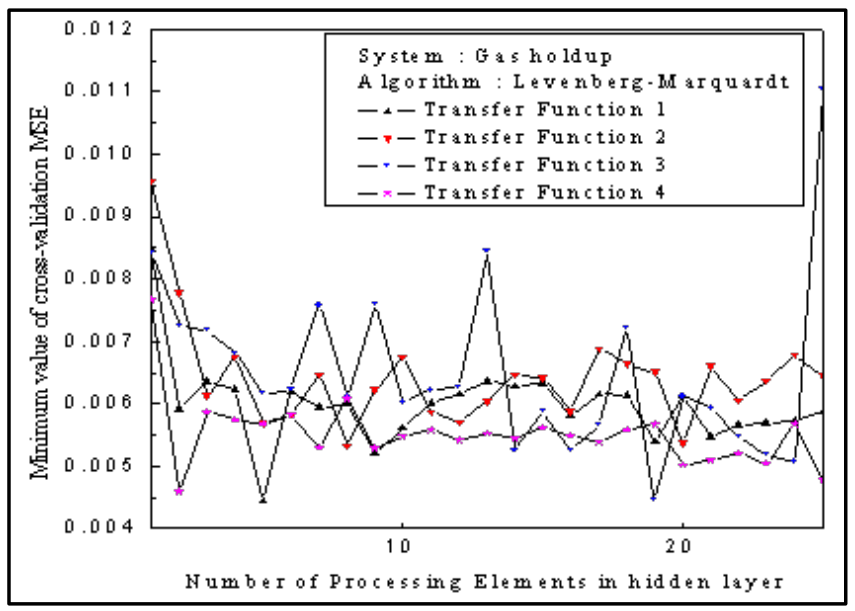

Figure 2. Variation of the minimum value of cross-validation MSE with the number of processing elements in the hidden layer for gas holdup for four different Transfer functions used in the hidden layer for BP algorithm in hidden and output layer 
Figures 2 and 3 show the variation of minimum value of MSE for cross-validation with the number of processing elements in the hidden layer for gas holdup and pressure drop respectively. Four different transfer functions were used in the hidden layer for both cases, where LM and BP algorithms were used in the hidden layer and output layer respectively. Similar procedure was followed for all three types of algorithms used for the prediction of gas holdup and pressure drop. The number of processing element is considered optimum where the MSE value is minimum. Table 2 shows the optimum number of processing elements in the training section of the ANN for both gas holdup and pressure drop.

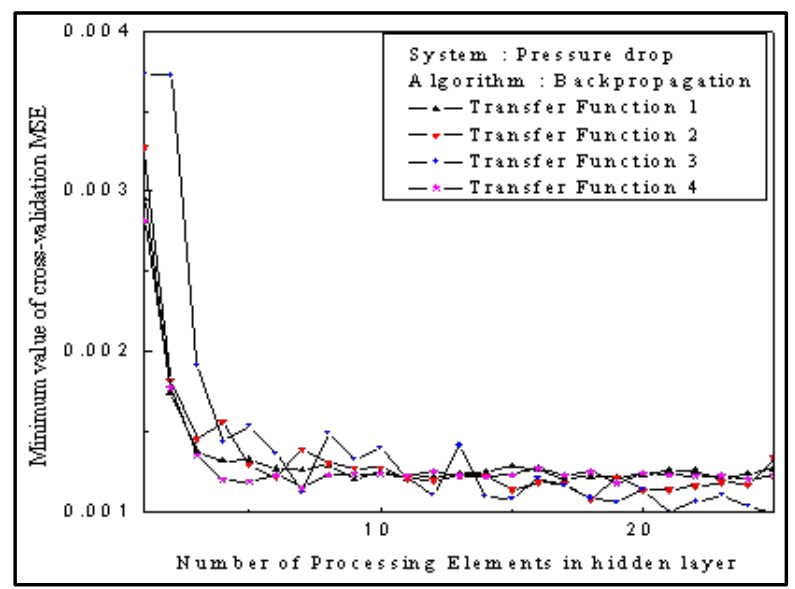

Figure 3. Variation of the minimum value of cross-validation MSE with the number of processing elements in the hidden layer for pressure drop for four different Transfer functions used in the hidden layer for BP algorithm in hidden and output layer

The threshold value of the MSE for cross-validation for all three networks had been kept as 0.001 .

The stopping criterion was also added for all three different algorithms used. In total the training using BP algorithm was initially set for 32000 epochs. If there was no improvement of the value of cross-validation MSE for 20000 epochs, then the training was stopped for training using BP network. Similarly the training using SCG and LM algorithm was initially set for 20000 and 1000 epochs respectively. If there was no improvement of the value of cross-validation MSE for 5000 epochs for training using SCG and 300 epochs for training using LM algorithm, then the training was stopped.

Table 3 shows the minimum value of cross-validation MSE reached during training for both holdup and pressure drop. The network is considered optimized at that particular point where the cross-validation error recorded its minimum value.

These optimum numbers of processing elements are used for further subsequent analysis.

Figure 4 presents the training curves for SCG algorithm using the four different transfer functions in hidden layer for the prediction of pressure drop. Similar trend was observed for the other two algorithms also. The decrease in the average MSE values matches the desired result for a standard neural network training curve. However this decrease does not indicate the optimum training performance of the network but it is the cross-validation curve that indicates the optimum performance.

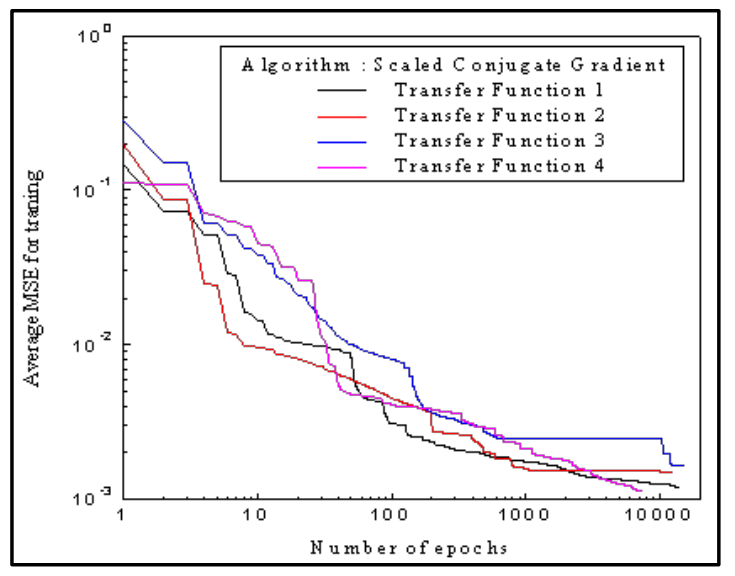

Figure 4. Variation in the MSE for training using SCG algorithm vs. the numbers of epochs for the prediction of pressure drop

Table 2. Optimum numbers of processing elements in the hidden layer for four different transfer functions

\begin{tabular}{|c|c|c|c|c|}
\hline \multirow[t]{2}{*}{ Transfer Function in Hidden Layer } & \multirow[t]{2}{*}{ Equation } & \multirow[t]{2}{*}{ Algorithm } & \multicolumn{2}{|c|}{$\begin{array}{c}\text { Optimum Number of Processing Ele- } \\
\text { ments }\end{array}$} \\
\hline & & & $\alpha_{\mathrm{g}}$ & $\Delta \mathrm{P}_{\mathrm{tp}} / \mathrm{L}$ \\
\hline \multirow[b]{3}{*}{ Transfer Function 1} & \multirow{3}{*}{$f_{1 h}(x)=\tanh \beta x=\frac{e^{\beta x}-e^{-\beta x}}{e^{\beta x}+e^{-\beta x}}$} & BP & 3 & 17 \\
\hline & & LM & 5 & 4 \\
\hline & & SCG & 2 & 5 \\
\hline \multirow{3}{*}{ Transfer Function 2} & \multirow{3}{*}{$f_{2 h}(x)=\beta x$ Where $\begin{array}{c}\beta x=1 \text { for } \beta x>1 \\
\beta x=-1 \text { for } \beta x<-1\end{array}$} & BP & 3 & 18 \\
\hline & & LM & 8 & 21 \\
\hline & & SCG & 5 & 24 \\
\hline \multirow{3}{*}{ Transfer Function 3} & \multirow{3}{*}{$f_{3 h}(x)=\beta x$ Where $\begin{array}{r}\beta x=0 \text { for } \beta x<0 \\
\beta x=1 \text { for } \beta x>1\end{array}$} & $\mathrm{BP}$ & 15 & 25 \\
\hline & & LM & 19 & 16 \\
\hline & & SCG & 15 & 19 \\
\hline \multirow{3}{*}{ Transfer Function 4} & \multirow{3}{*}{$f_{4 h}(x)=\frac{1}{1+e^{-\beta x}}$} & $\mathrm{BP}$ & 15 & 7 \\
\hline & & LM & 2 & 22 \\
\hline & & SCG & 14 & 5 \\
\hline
\end{tabular}


Table 3. Performance of the best Neural Network on the basis of minimum value of MSE reached during Cross-validation

\begin{tabular}{|c|c|c|c|c|c|c|}
\hline \multirow{2}{*}{$\begin{array}{c}\text { Transfer Function } \\
\text { in Hidden Layer }\end{array}$} & \multicolumn{3}{|c|}{ Algorithm } & \multicolumn{3}{c|}{ SCG } \\
\cline { 2 - 7 } & \multicolumn{2}{|c|}{$\mathrm{BP}$} & \multicolumn{2}{|c|}{$\mathrm{LM}$} & $\Delta \mathrm{P}_{\mathrm{tp}} / \mathrm{L}$ & \multicolumn{2}{c|}{$\alpha_{\mathrm{g}}$} & $\Delta \mathrm{P}_{\mathrm{tp}} / \mathrm{L}$ \\
\hline & $\alpha_{\mathrm{g}}$ & $\Delta \mathrm{P}_{\mathrm{tp}} / \mathrm{L}$ & $\alpha_{\mathrm{g}}$ & 0.0010 & 0.0051 & 0.0010 \\
\hline 2 & 0.0057 & 0.0012 & 0.0045 & 0.0011 & 0.0049 & 0.0010 \\
\hline 3 & 0.0054 & 0.0011 & 0.0053 & 0.0013 & 0.0048 & 0.0009 \\
\hline 4 & 0.0052 & 0.0010 & 0.0045 & 0.0010 & 0.0048 & 0.0011 \\
\hline
\end{tabular}

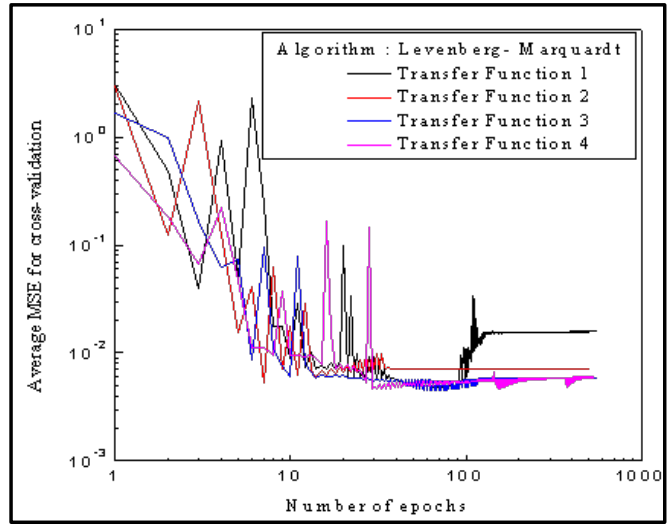

Figure 5. Variation in the MSE for cross-validation using LM algorithm vs. the numbers of epochs for the prediction of pressure drop

Figure 5 presents the cross-validation curves for LM algorithm using the four different transfer functions in hidden layer. It is clear from the curve that the curves reach a saturation point in training and then it remains constant or it does not change for the betterment of the performance of training even if the decrease in the value of MSE in the training curve continues. It is for this reason the stopping criterion was used for cross-validation. It is evident from the abrupt end of the training in Figures 4 and 5 before reaching the epoch number 20000 and 1000 respectively. Similar trend was also observed for the training with BP network also.

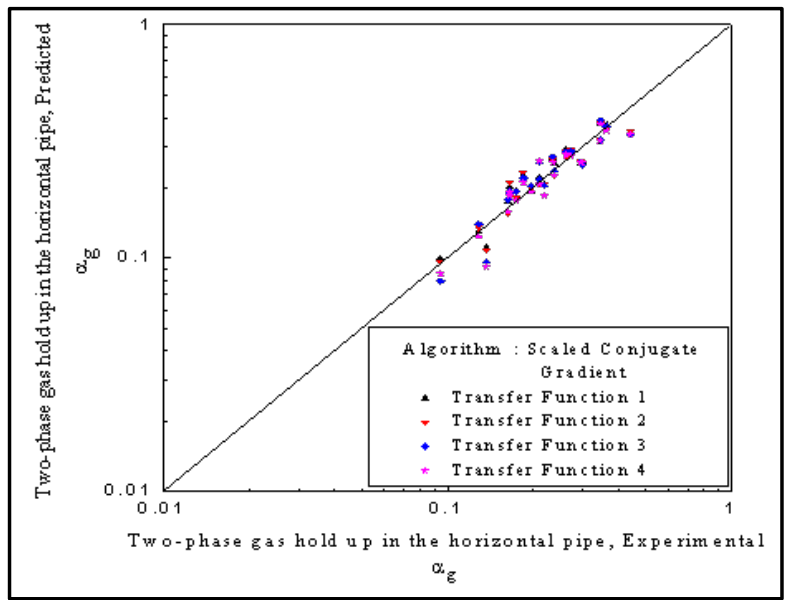

Figure 6. Comparison of two-phase gas hold up across the horizontal tube for prediction using SCG algorithm in hidden and output layer with four different transfer function in the hidden layer for testing

Figure 6 shows the comparison between the experimental to the predicted output for the four different transfer functions in the hidden layer for testing in case of gas hold up using SCG algorithms. Figure 7 shows the comparison be- tween the experimental to the predicted output for the four different transfer functions in the hidden layer for testing in case of pressure drop using LM algorithms.

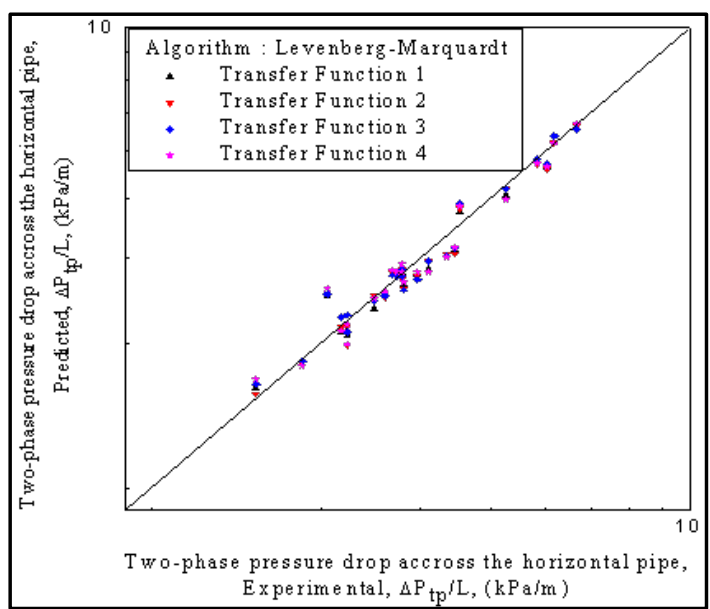

Figure 7. Comparison of two-phase pressure drop across the horizontal tube for prediction using LM algorithm in hidden and output layer with four different transfer function in the hidden layer for testing

Table 4. Performance of the best Neural Networks for the prediction of gas holdup for four different Transfer functions in case of Testing

\begin{tabular}{|c|c|c|c|c|}
\hline Transfer & & \multicolumn{3}{|c|}{ Algorithm } \\
\cline { 2 - 5 } $\begin{array}{c}\text { Function } \\
\text { in Hid- } \\
\text { den } \\
\text { Layer }\end{array}$ & $\begin{array}{c}\text { Measurement } \\
\text { Type }\end{array}$ & $\begin{array}{c}\text { Back- } \\
\text { propagation }\end{array}$ & $\begin{array}{c}\text { Levenberg- } \\
\text { Marquardt }\end{array}$ & $\begin{array}{c}\text { Scaled } \\
\text { Conjugate } \\
\text { Gradient }\end{array}$ \\
\hline \multirow{2}{*}{$\begin{array}{c}\text { Transfer } \\
\text { Function } \\
1\end{array}$} & AARE & 0.090430 & 0.084924 & 0.108509 \\
\cline { 2 - 5 } & $\mathrm{SD}(\sigma)$ & 0.071715 & 0.066647 & 0.067787 \\
\cline { 2 - 5 } & $\mathrm{MSE}$ & 0.000850 & 0.000706 & 0.001065 \\
\cline { 2 - 5 } & $\mathrm{CCC}(\mathrm{R})$ & 0.936184 & 0.948621 & 0.920925 \\
\hline \multirow{3}{*}{$\begin{array}{c}\text { Transfer } \\
\text { Function } \\
2\end{array}$} & $\mathrm{AARE}$ & 0.107320 & 0.108411 & 0.101549 \\
\cline { 2 - 5 } & $\mathrm{SD}(\sigma)$ & 0.067273 & 0.073213 & 0.082658 \\
\cline { 2 - 5 } & $\mathrm{MSE}$ & 0.001041 & 0.001018 & 0.001018 \\
\hline \multirow{3}{*}{$\begin{array}{c}\text { Transfer } \\
\text { Function } \\
3\end{array}$} & $\mathrm{CCC}(\mathrm{R})$ & 0.921524 & 0.923092 & 0.923189 \\
\cline { 2 - 5 } & $\mathrm{AARE}$ & 0.110109 & 0.118054 & 0.114825 \\
\cline { 2 - 5 } & $\mathrm{SD}(\sigma)$ & 0.080493 & 0.092129 & 0.073951 \\
\cline { 2 - 5 } & $\mathrm{MSE}$ & 0.001099 & 0.001296 & 0.001103 \\
\hline \multirow{2}{*}{$\begin{array}{c}\text { Transfer } \\
\text { Function } \\
4\end{array}$} & $\mathrm{AARE}$ & 0.916794 & 0.903497 & 0.916153 \\
\cline { 2 - 5 } & $\mathrm{SD}(\sigma)$ & 0.092641 & 0.093234 & 0.098421 \\
\cline { 2 - 5 } & $\mathrm{MSE}$ & 0.000926 & 0.073871 & 0.082890 \\
\cline { 2 - 5 } & $\mathrm{CCC}(\mathrm{R})$ & 0.930569 & 0.926581 & 0.925216 \\
\hline
\end{tabular}

The proximity of the data points to the reference line in Figures 6 and 7 indicate that the training was accurate for both gas holdup and pressure drop. This result can be verified from the statistical analysis presented in Tables 4 and 5 for gas holdup and pressure drop respectively. It is now indicative from these figures that the network can be used for 
final prediction.

Table 5. Performance of the best Neural Networks for the prediction of pressure drop for four different Transfer functions in case of Testing

\begin{tabular}{|c|c|c|c|c|}
\hline \multirow{2}{*}{$\begin{array}{c}\text { Transfer } \\
\text { Function } \\
\text { in Hid- } \\
\text { den } \\
\text { Layer }\end{array}$} & \multirow[b]{2}{*}{$\begin{array}{l}\text { Measurement } \\
\text { Type }\end{array}$} & \multicolumn{3}{|c|}{ Algorithm } \\
\hline & & $\begin{array}{c}\text { Back- } \\
\text { propagation }\end{array}$ & $\begin{array}{l}\text { Levenberg- } \\
\text { Marquardt }\end{array}$ & $\begin{array}{c}\text { Scaled } \\
\text { Conjugate } \\
\text { Gradient }\end{array}$ \\
\hline \multirow{4}{*}{$\begin{array}{c}\text { Transfer } \\
\text { Function } \\
1\end{array}$} & AARE & 0.046471 & 0.052851 & 0.053139 \\
\hline & $\mathrm{SD}(\sigma)$ & 0.049124 & 0.045764 & 0.049825 \\
\hline & MSE & 0.043197 & 0.047604 & 0.048153 \\
\hline & $\mathrm{CCC}(\mathrm{R})$ & 0.985995 & 0.985342 & 0.985077 \\
\hline \multirow{4}{*}{$\begin{array}{c}\text { Transfer } \\
\text { Function } \\
2\end{array}$} & AARE & 0.050923 & 0.051074 & 0.052552 \\
\hline & $\mathrm{SD}(\sigma)$ & 0.043452 & 0.052885 & 0.045107 \\
\hline & MSE & 0.048502 & 0.051778 & 0.044430 \\
\hline & CCC (R) & 0.985155 & 0.984029 & 0.986698 \\
\hline \multirow{4}{*}{$\begin{array}{c}\text { Transfer } \\
\text { Function } \\
3\end{array}$} & AARE & 0.051514 & 0.052352 & 0.067349 \\
\hline & $\mathrm{SD}(\sigma)$ & 0.046650 & 0.049904 & 0.049764 \\
\hline & MSE & 0.049918 & 0.048652 & 0.072142 \\
\hline & CCC (R) & 0.984423 & 0.983875 & 0.981974 \\
\hline \multirow{4}{*}{$\begin{array}{c}\text { Transfer } \\
\text { Function } \\
4\end{array}$} & AARE & 0.049044 & 0.058184 & 0.049855 \\
\hline & $\mathrm{SD}(\sigma)$ & 0.045002 & 0.056398 & 0.044501 \\
\hline & MSE & 0.043868 & 0.057469 & 0.045236 \\
\hline & CCC (R) & 0.986066 & 0.981417 & 0.986130 \\
\hline
\end{tabular}

Tables 4 and 5 present the performance of Neural Network for testing for gas holdup and pressure drop respectively. The low value of the Average Absolute Relative Error (AARE), Standard Deviation $(\sigma)$ and MSE also shows the closeness between desired and the predicted data, i.e., the accuracy of the results in the different systems. It can be observed clearly from Tables 4 and 5 that the network is appropriate for final prediction.

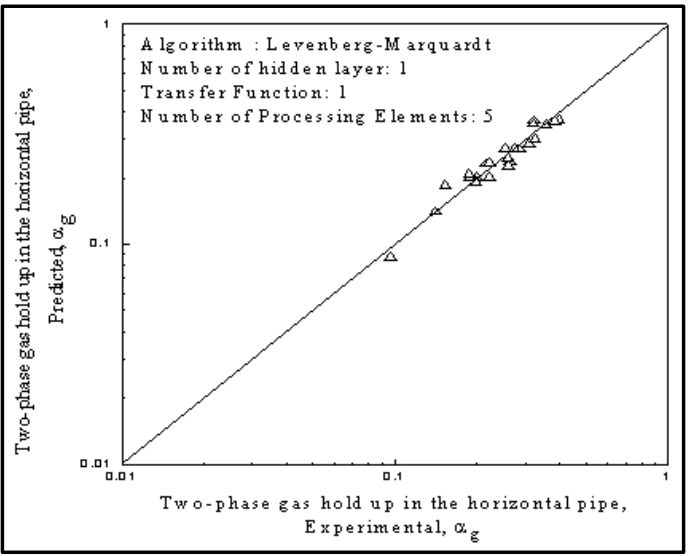

Figure 8. Comparison of two-phase hold up across the vertical coil for prediction using LM algorithm in hidden and output layer with transfer function 1 in the hidden layer

Tables 6 and 7 present the performance of Neural Network for final prediction for both holdup and pressure drop respectively. It is also clear from these tables that the Cross Correlation Co-efficient value is nearly 0.92 and above for prediction of gas hold up and is nearly 0.98 and above for prediction of pressure drop. The low value of the Average Absolute Relative Error (AARE), Standard Deviation $(\sigma)$ and MSE also shows the closeness between desired and the predicted data, i.e., accuracy of the result in the different systems. This result indicates that the performance of the network output is excellent.

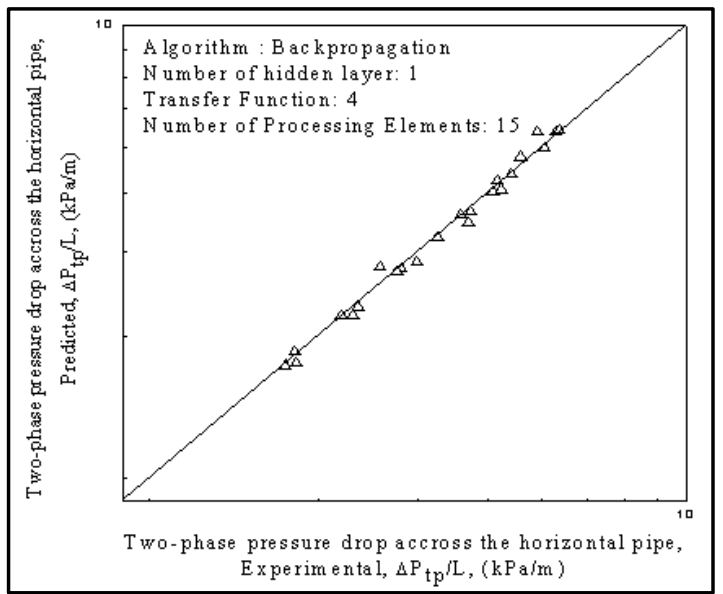

Figure 9. Comparison of two-phase pressure drop across the vertical coil for prediction using BP algorithm in hidden and output layer with transfer function 4 in the hidden layer

The Chi-square test confirms that the best network for prediction of gas hold up is the transfer function 1 with 5 processing elements using LM algorithm in the hidden and output layer. The Chi-square test also confirms that the best network for prediction of gas hold up is the transfer function 4 with 15 processing elements using BP algorithm in the hidden and output layer.

Table 6. Performance of the best Neural Networks for different Transfer functions in case of final prediction of gas holdup

\begin{tabular}{|c|c|c|c|c|}
\hline \multirow{2}{*}{$\begin{array}{c}\text { Transfer } \\
\text { Function } \\
\text { in Hidden } \\
\text { Layer }\end{array}$} & \multirow[b]{2}{*}{$\begin{array}{c}\text { Measurement } \\
\text { Type }\end{array}$} & \multicolumn{3}{|c|}{ Algorithm } \\
\hline & & $\begin{array}{c}\text { Back- } \\
\text { propagation }\end{array}$ & $\begin{array}{l}\text { Levenberg- } \\
\text { Marquardt }\end{array}$ & $\begin{array}{c}\text { Scaled } \\
\text { Conjugate } \\
\text { Gradient }\end{array}$ \\
\hline \multirow{5}{*}{$\begin{array}{c}\text { Transfer } \\
\text { Function } \\
1\end{array}$} & AARE & 0.091266 & 0.075573 & 0.106422 \\
\hline & $\operatorname{SD}(\sigma)$ & 0.092439 & 0.047312 & 0.069971 \\
\hline & MSE & 0.000672 & 0.000471 & 0.000759 \\
\hline & $\mathrm{CCC}(\mathrm{R})$ & 0.942542 & 0.958949 & 0.935684 \\
\hline & $\chi^{2}$ & 0.062886 & 0.041274 & 0.069060 \\
\hline \multirow{5}{*}{$\begin{array}{c}\text { Transfer } \\
\text { Function } \\
2\end{array}$} & AARE & 0.106728 & 0.101460 & 0.092272 \\
\hline & $\mathrm{SD}(\sigma)$ & 0.099315 & 0.071613 & 0.078079 \\
\hline & MSE & 0.000725 & 0.000775 & 0.000622 \\
\hline & $\mathrm{CCC}(\mathrm{R})$ & 0.942603 & 0.931033 & 0.948149 \\
\hline & $\chi^{2}$ & 0.071326 & 0.071842 & 0.058631 \\
\hline \multirow{5}{*}{$\begin{array}{c}\text { Transfer } \\
\text { Function } \\
3\end{array}$} & AARE & 0.103239 & 0.100667 & 0.098528 \\
\hline & $\mathrm{SD}(\sigma)$ & 0.080199 & 0.068727 & 0.082401 \\
\hline & MSE & 0.000734 & 0.000841 & 0.000666 \\
\hline & $\mathrm{CCC}(\mathrm{R})$ & 0.940091 & 0.936302 & 0.944430 \\
\hline & $\chi^{2}$ & 0.069272 & 0.076576 & 0.064841 \\
\hline \multirow{5}{*}{$\begin{array}{c}\text { Transfer } \\
\text { Function } \\
4\end{array}$} & AARE & 0.087570 & 0.104571 & 0.096417 \\
\hline & $\mathrm{SD}(\sigma)$ & 0.079781 & 0.048844 & 0.074468 \\
\hline & MSE & 0.000604 & 0.000878 & 0.000847 \\
\hline & $\mathrm{CCC}(\mathrm{R})$ & 0.949548 & 0.929649 & 0.933941 \\
\hline & $\chi^{2}$ & 0.055872 & 0.077033 & 0.079276 \\
\hline
\end{tabular}

Figure 8 shows the comparison between the experimental to the predicted output for the network trained with LM 
algorithm in the hidden and output layer, using transfer function 1 in the hidden layer in case of gas hold up. Figure 9 shows the comparison between the experimental to the predicted output for the network trained with $\mathrm{BP}$ algorithm in the hidden and output layer using transfer function 4 in the hidden layer in case of pressure drop. These comparisons prove the effectiveness of the Neural Network analysis.

Table 7. Performance of the best Neural Networks for different Transfer functions in case of final prediction of pressure drop

\begin{tabular}{|c|c|c|c|c|}
\hline $\begin{array}{c}\text { Transfer } \\
\text { Function } \\
\text { in Hid- } \\
\text { den } \\
\text { Layer }\end{array}$ & $\begin{array}{c}\text { Measurement } \\
\text { Type }\end{array}$ & $\begin{array}{c}\text { Back- } \\
\text { propagation }\end{array}$ & $\begin{array}{c}\text { Levenberg- } \\
\text { Marquardt }\end{array}$ & $\begin{array}{c}\text { Scaled } \\
\text { Conjugate } \\
\text { Gradient }\end{array}$ \\
\cline { 2 - 5 } & AARE & 0.030535 & 0.032557 & 0.031880 \\
\cline { 2 - 5 } Transfer \\
\cline { 2 - 5 } $\begin{array}{c}\text { Function } \\
1\end{array}$ & $\mathrm{SD}(\sigma)$ & 0.029594 & 0.028402 & 0.030316 \\
\cline { 2 - 5 } & $\mathrm{MSE}$ & 0.031182 & 0.029622 & 0.026532 \\
\cline { 2 - 5 } & $\mathrm{CCC}(\mathrm{R})$ & 0.991180 & 0.991500 & 0.991983 \\
\cline { 2 - 5 } & $\chi^{2}$ & 0.160456 & 0.166903 & 0.154370 \\
\hline \multirow{4}{*}{$\begin{array}{c}\text { Transfer } \\
\text { Function }\end{array}$} & $\mathrm{AARE}$ & 0.032572 & 0.038887 & 0.037129 \\
\cline { 2 - 5 } & $\mathrm{SD}(\sigma)$ & 0.026949 & 0.031369 & 0.031249 \\
\cline { 2 - 5 } & $\mathrm{MSE}$ & 0.029142 & 0.032413 & 0.027316 \\
\cline { 2 - 5 } & $\mathrm{CCC}(\mathrm{R})$ & 0.992230 & 0.990488 & 0.992732 \\
\hline \multirow{4}{*}{$\begin{array}{c}\text { Transfer } \\
\text { Function } \\
3\end{array}$} & $\chi^{2}$ & 0.155365 & 0.199201 & 0.174421 \\
\cline { 2 - 5 } & $\mathrm{AARE}$ & 0.036732 & 0.041200 & 0.042827 \\
\cline { 2 - 5 } & $\mathrm{SD}(\sigma)$ & 0.031993 & 0.029720 & 0.031144 \\
\cline { 2 - 5 } & $\mathrm{MSE}$ & 0.038905 & 0.033229 & 0.039119 \\
\cline { 2 - 5 } & $\mathrm{CCC}(\mathrm{R})$ & 0.988411 & 0.989875 & 0.989323 \\
\hline \multirow{4}{*}{$\begin{array}{c}\text { Transfer } \\
\text { Function } \\
4\end{array}$} & $\chi^{2}$ & 0.207784 & 0.193134 & 0.238212 \\
\cline { 2 - 5 } & $\mathrm{AARE}$ & $\mathbf{0 . 0 2 8 7 6 7}$ & 0.032970 & 0.032194 \\
\cline { 2 - 5 } & $\mathrm{SD}(\sigma)$ & $\mathbf{0 . 0 2 5 7 3 4}$ & 0.031528 & 0.026618 \\
\cline { 2 - 5 } & $\mathrm{MSE}$ & $\mathbf{0 . 0 2 5 4 3 2}$ & 0.024983 & 0.027299 \\
\cline { 2 - 5 } & $\mathrm{CCC}(\mathrm{R})$ & $\mathbf{0 . 9 9 3 1 1 7}$ & 0.992255 & 0.991913 \\
\hline \multirow{4}{*}{$\chi^{2}$} & $\mathbf{0 . 1 2 9 6 0 3}$ & 0.155731 & 0.150052 \\
\hline
\end{tabular}

Tables 6 and 7 indicate that the value of the Average Absolute Relative Error (AARE), Standard Deviation $(\sigma)$ and Cross Correlation Co-efficient (R) for the final prediction shows that the best network for prediction of gas hold up is the transfer function 1 with 5 processing elements using LM algorithm in the hidden and output layer and the best network for prediction of pressure drop is the transfer function 4 with 15 processing elements using $\mathrm{BP}$ algorithm in the hidden and output layer.

\section{Conclusions}

A neural network based model was developed for the prediction of gas holdup and pressure drop for gas non-Newtonian liquid flow through horizontal pipe. A multilayer perceptron (one hidden layer) with three different algorithms namely Backpropagation, scaled conjugate gradient and Levenberg-Marquardt were used for this analysis. The ANN model accurately predicts the gas hold up and pressure drop across the horizontal pipe. The Chi-square test confirms that the best network for prediction of gas hold up is the transfer function 1 with 5 processing elements using
Levenberg-Marquardt algorithm in the hidden and output layer. The Chi-square test also confirms that the best network for prediction of pressure drop is the transfer function 4 with 15 processing elements using Backpropagation algorithm in the hidden and output layer. Hence the developed ANN predictability should be useful in the scale-up of commercial pipeline.

\section{REFERENCES}

[1] P. L. Spedding, and D R. Spence, "Prediction of Holdup in Two-Phase Flow,” Int. J Engg. Fluid Mech., vol. 1, pp. 67-82, 1988.

[2] Wallis, G. B., One dimensional two-phase flow, McGrew-Hill Book Co. Inc., New York, 1969.

[3] G. W. Govier, and K. Aziz, The Flow of Complex Mixtures in Pipes, Van Nostran Reinhold, New York City, 1972.

[4] G. Hestroni, Handbook of Multiphase Systems, Hemisphere Publishing. Corp., Washington, DC, 1982.

[5] C. T. Crowe, Multiphase Flow Handbook, CRC, 2006.

[6] H. C. Ward, and J. M. Dallavalle, "Co-Current Turbulent-Turbulant Flow of Air and Water-Clay Suspensions in Horizontal Pipes," Chem. Eng. Prog. Symp., vol. 10, pp. 1-14, 1954.

[7] D. R. Oliver, and A. Young-Hoon, "Two-phase non-Newtonian flow, Part I: Pressure drop and holdup," Trans. IChemE, vol. 46, pp. 106-115, 1968.

[8] R. W. Lockhart, and R. C., Martinelli, "Proposed correlation of data for isothermal two-phase, two-component flow in pipes," Chem. Engg. Progress, vol. 45, pp. 39-48, 1949.

[9] R. G. Rosehart, E. Rhodes, and D. S. Scott, "Studies of gas-liquid (non-Newtonian) slug flow: void fraction meter, void fraction and slug characteristics," Chem. Eng. J., 10(1), pp. 57-64, 1975.

[10] R. Mahalingam, and M. A. Valle, "Momentum Transfer In Two-Phase Flow Of Gas-Pseudo-Plastic Liquid Mixtures," Ind. Eng. Chem. Fundam. vol. 11, pp. 470-477, 1972.

[11] R. G. Rosehart, D. Scott, and E. Rhodes, "Gas-liquid slug flow with drag-reducing polymer solutions," AIChE J., vol. 18, pp. 744-750, 1972.

[12] R. P. S. Srivastava, and G. S. R. Narasimhamurthy, "Hydrodynamics of non-Newtonian two-phase flow in pipes," Chem. Eng. Sci., 28(2), 553-558, 1973.

[13] R. P. S. Srivastava, and G. S. R. Narasimhamurthy, "Void Fraction and Flow Pattern during Two-Phase Flow of Pseudoplastic Fluids," Chem. Eng. J., 21(2), 165-176, 1981.

[14] K. P. Tyagi, and R. P. S. Srivastava, "Flow behavior of non-Newtonian liquid-air in annular flow," Chem. Eng. J., 11(2), 147-152, 1976.

[15] L. Otten, and A. S. Fayed, "Pressure drop and drag reduction in two-phase non-Newtonian slug flow," Can. J. Chem. Eng., 54, 111-114, 1976. 
[16] L. Otten, and A. S. Fayed, "Slug Velocity and Slug Frequency Measurements in Concurrent Air/non-Newtonian Slug Flow," Trans. Instn. Chem. Engrs., 55, 64-67, 1977.

[17] N. I. Heywood, and J. F. Richardson, "Head loss reduction by gas injection for highly shear-thinning suspensions in horizontal pipe flow," Proc. Hydrotransport 5, Hanover, F. R. G., Paper C1, pp. 1-22, BHRA,1978.

[18] S. I. Farooqi, N. I. Heywood, and J. F. Richardson, "Drag reduction by air injection for suspension flow in horizontal pipe line,” Trans. Instn. Chem. Engrs., 58, 16-27, 1980.

[19] F. G. Eisenberg, and C. B. Weinberger, "Annular two-phase flow of gases and non-Newtonian liquids," AIChE J., 25(2), 240-246, 1979.

[20] N. Heywood, and M. E. Charles, "The Stratified Flow of Gas and non-Newtonian Liquid in Horizontal Pipes," Int. J. Multiphase Flow, vol. 5, pp. 341-352, 1979.

[21] S. I. Farooqi, and J. F. Richardson, "Horizontal flow of air and liquid (Newtonian and non-Newtonian) in a smooth pipe. Part I: A correlation for average liquid holdup," Trans. IChemE, vol. 60, pp. 292-322, 1982.

[22] S. I. Farooqi, and J. F. Richardson, "Horizontal Flow of air and liquid (Newtonian and non-Newtonian) in a smooth pipe. Part II: Average pressure drop," Trans. IChemE, vol. 60, pp. 323-333, 1982.

[23] R. P. Chhabra, S. I. Farooqi, J. F. Richardson, and A. P. Wardle, "Co-current flow of air and shear-thinning suspensions in pipes of large diameter," Chem. Eng. Res. Des., vol. 61, pp. 56-61, 1983.

[24] R. P. Chhabra, S. I. Farooqi, and J. F. Richardson, "Isothermal two-phase of air and aqueous polymer solutions in a smooth horizontal pipe," Chem. Eng. Res. Des., vol. 62, pp. 22-31, 1984.

[25] S. K. Das, M. N. Biswas, and A. K. Mitra, "Pressure Loses in Two-Phase Gas-Non-Newtonian Liquid Flow in Horizontal Tube,” J. Pipelines, vol. 7, pp. 307-325, 1989.

[26] S. K. Das, M. N. Biswas, and A. K. Mitra, "Holdup for two-phase flow of gas-non-newtonian liquid mixtures in horizontal and vertical pipes," Can. J. Chem. Eng., vol. 70, pp. 431-437, 1992.

[27] M. Dziubinski, "A general correlation for the two-phase pressure drop in intermittent flow of gas and non-newtonian liquid mixtures in a pipe," Trans. Chem. Eng. Res. Des., vol. 73, pp. 528-533, 1995.

[28] D. Jinming, and Z. Jingxuan, "Studies on frictional pressure drop of gas-non-Newtonian fluid two-phase flow in the vacuum sewers," Civil Engg. Environ. Systems, vol. 23, pp. $1-10,2006$

[29] M. J. Ruiz-Viera, M. A. Delgado, J. M. France, M. C. Sa'Nchez, and C. Gallegos, "On the drag reduction for the two-phase horizontal pipe flow of highly viscous non-newtonian liquid/air mixtures: Case of lubricating grease,” Int. J. Multiphase Flow, vol. 32, pp. 232-247, 2006.

[30] J. Xu, Y. Wu, Z. Shi, L. Lao, and D. Li, "Studies on two-phase co-current air/non-Newtonian shear-thinning fluid flows in inclined smooth pipes," Int. J. Multiphase Flow, vol. 33, pp. 948-969, 2007.
[31] J. Xu, Y. Wu, D. Li, and H. Dong, "Effects of non-Newtonian liquid properties on pressure drop during horizontal gas-liquid flow," J. Cent. South Univ. Technol., 14(s1), 112-115, 2007.

[32] J. Xu, Y. Wu, H. Li, J. Guo, and Y. Chang, "Study of drag reduction by gas injection for power-law fluid flow in horizontal stratified and slug flow regimes," Chem. Engg. J., vol. 147, pp. 235-244, 2009.

[33] N. Jia, M. Gourma, and C. P. Thompson, "Non-Newtonian multi-phase flows: On drag reduction, pressure drop and liquid wall friction factor," Chem. Engg. Sci., vol. 66, pp. 4742-4756, 2011

[34] R. Plippman, "An introduction to computing with neural nets," IEEE ASSP Mag., vol. 4, pp. 4-22, 1987.

[35] S. Cai, H. Toral, J. Qui, and J. S. Archer, "Neural network based objective flow regime identification in air-water two phase flow," Can. J. Chem. Engg., vol. 72, pp. 440-445, 1994.

[36] M. Leib, P. L. Mills, J. J. Lerou, and J. J. Turner, "Evaluation of neural networks for simulation of three-phase bubble column reactors," Trans. IChemE, vol. 73, pp. 690-696, 1995.

[37] Z. Bensetiti, F. Larachi, B. P. A. Grandjean, and G. Wild, "Liquid saturation in concurrent upflow fixed-bed reactors: a state-of-the-art correlation," Chem. Engg. Sci., vol. 52, pp. 4239-4247, 1997.

[38] F. Larachi, Z. Bensetiti, B. P. A. Grandjean, and G. Wild, "Two-phase frictional pressure drop in flooded-bed reactors: a state-of-the-art correlation," Chem. Eng. Technol., vol.21, pp. 887-893, 1998.

[39] S. Piche, F. Larachi, and B. P. A. Grandjean, "Improved Liquid Hold-up Correlation for Randomly Packed Towers," Chem. Eng. Res. Des., vol. 79, pp. 71-80, 2001.

[40] L. lliuta, B. P. A. Grandjean, and F. Larachi, "Hydrodynamics of trickle-flow reactors: updated slip functions for slit models," Chem. Eng. Res. Des., vol. 80, pp. 195-200, 2002.

[41] M.E. Shippen, and S.S.L. Scott, "A neural network model for prediction of liquid holdup in two-phase horizontal flow," SPE 77499, Proc. SPE Annual Technical Conference and Exhibition, San Antonio, Texas, September - October, 2002.

[42] E. A. Osman, and M. A. Aggour, "Artificial neural network model for accurate prediction of pressure drop in horizontal and near-horizontal-multiphase flow," Pet. Sci. Technol., vol. 20, pp. 1-15, 2002.

[43] M.R. Malayeri, H. M uller-Steinhagen, and J. M. Smith, "Neural network analysis of void fraction in air/water two-phase flows at elevated temperatures," Chem. Engg. Sci., vol. 42 , pp. 587-597, 2003.

[44] A.Alizadehdakhel, M. Rahimi, J. Sanjari, and A. A. Alsairafi, "CFD and artificial neural network modeling of two-phase flow pressure drop," Int. Commun. Heat Mass Transfer, vol. 36 , pp. 850-856, 2009.

[45] A. Shaikh, and M. Al-Dahhan, "Development of an artificial neural network correlation for prediction of overall gas holdup in bubble column reactors," Chem. Engg. Proc., vol. 42, pp. 599-610, 2009. 
[46] S. Nasseh, A. Mohebbi, A. Sarrafi, and M. Taheri, "Estimation of pressure drop in venture scrubbers based on annular two-phase flow model, artificial neural networks and genetic algorithm," vol. 150, pp. 131-138, 2009.

[47] N. Bar, T. K. Bandyopadhyay, M. N. Biswas, and S. K. Das, "Prediction of Pressure Drop using Artificial Neural Network for non-Newtonian Liquid Flow through Piping Components," J. Pet. Sci. Eng., vol. 71, pp. 187-194, 2010.

[48] N. Bar, M. N. Biswas, and S. K. Das, "Prediction of Pressure Drop using Artificial Neural Network for Gas-non-Newtonian Liquid Flow through Piping Components," Ind. Eng. Chem. Res., vol. 49, pp. 9423-9429, 2010.

[49] N. Bar, M. N. Biswas, and S. K. Das, "Frictional Pressure Drop Prediction Using ANN for Gas-non-Newtonian Liquid Flow through $45^{\circ}$ Bend," Int. J. Artificial Intelligent Systems and Machine Learning, vol. 3, pp. 608-613, 2011.

[50] S. Haykin, Neural networks - a comprehensive foundation, 2nd Ed. Prentice-Hall, USA, 1999.

[51] N. Bar, and S. K. Das, "Comparative study of friction factor by prediction of frictional pressure drop per unit length using empirical correlation and ANN for gas-non-Newtonian liquid flow through $180^{\circ}$ circular bend," Int. Rev. Chem. Engg., vol. 3, pp. 628-643, 2011.
[52] S. K. Das, (1988) "Studies on two-phase gas-non-Newtonian liquid flow in horizontal, vertical tubes and bends," Ph.D. thesis, Dept. Chem. Engg., Indian Institute of Technology, Kharagpur, India.

[53] B. Widrow, R. G. Winter, and R. A. Baxter, "Layered Neural Nets for Pattern Recognition," IEEE Trans. Acoustics, Speech and Signal Processing," vol. 36, pp. 1109-1118, 1988.

[54] E. Barnard, and L. Wessels, "Extrapolation and interpolation in neural network classifiers," IEEE Control Systems, vol. 12, pp. 50-53, 1992.

[55] H. White, "Connectionist nonparametric regression: multilayer feed-forward networks can learn arbitrary mapping," Neural Networks, vol. 3, pp. 535-549, 1990.

[56] S. Walczak, "Developing neural nets currency trading," Artificial Intelligence in Finance, vol. 2, pp. 27-34, 1995.

[57] A. Bansal, R. J. Kanuffman, and R. R. Weitz, "Comparing the modeling performance of regression and neural networks as data quality varies: a buisnessvalue approach," J. Manag. Information Systems, vol. 10, pp. 11-32, 1993.

[58] S. Tamura, and M. Tateishi, "Capabilities of four layered feedforward neural network: four layers versus three," IEEE Trans. Neural Net., vol. 8, pp. 251-255, 1997. 